\title{
Low cost safe water for the world: a practical interim solution
}

\author{
Reiff F, Roses M, Venczel L, Quick R, Will V
}

\begin{abstract}
A very large segment of the world's population is without a microbiologically safe water supply. It is estimated that in Latin America more than $40 \%$ of the population is utilizing water of dubious quality for human consumption. This figure is probably even higher in Africa and areas of southeast Asia. Water used for drinking and food preparation can be an important route of transmission for many of the most widespread and debilitating of the diseases that afflict humans. The cholera pandemic which struck Latin America in January 1991, and has become endemic in many of the countries, continues to exemplify the public health significance of contaminated drinking water. Ideally, this neglected segment of the world's population should be served with piped water systems that provide a continuous supply of microbiologically safe water, but this would require such enormous investments of financial and human resources that it is not reasonable to expect that it will be accomplished. Interim practical measures to assure microbio-logically safe water are necessary.
\end{abstract}

The public health intervention to accomplish this is described in this paper and has an annual per family cost of which ranges between $\$ 1.50$ and $\$ 4$. It consists of providing individual households with one or preferably two suitable water containers in which to disinfect and store the essential quantities of water that need to be free of pathogens, with the containers of a design that will preclude recontamination of the contents and enable the production and distribution of the water disinfectants to be managed at the local level. It includes the necessary component of public education, promotion and involvement to establish the sustainability of the measures as a community-based endeavor.

Investigation and demonstration projects are being carried out in 11 countries to determine and perfect and appropriate intervention, and it has been proven that it is economically, technically and socially feasible to assure microbiologically safe water for the world's population that is threatened by waterborne diseases. Carefully controlled microbiological analysis of the untreated and treated water shows that waterborne pathogens can be destroyed or inactivated, and carefully controlled epidemiological studies being carried out by the Centers for Disease Control and Prevention show that this intervention achieves considerable reduction in the incidence of waterborne disease.

It is recommended that all developing countries initiate programs to replicate the health measure described in this paper in order to test its validity and to adapt it to their local conditions.

\section{Background}

THE Pan American Health Organization (PAHO) estimated in 1994 that $41 \%$ of the population of Latin America and the Caribbean (LAC) was consuming drinking water 
that was microbiologically unsafe or was of dubious microbial quality more than $10 \%$ of the time (1). Approximately half of the affected households are connected to water supply systems that do not have adequate, reliable treatment, are intermittently pressurized, or lack the integrity necessary to preclude microbial contamination; the other half relies on non-piped water supplies that are microbially contaminated. This means that some 190 million people of the LAC countries are threatened by diseases transmitted through drinking water. The proportion of the population in the developing countries of Africa and in the less developed countries of southeast Asia that is without microbiologically safe water is even higher (2).

The public health significance of the microbiological quality of water and disinfection deficiency is exemplified by the continuing cholera pandemic that first afflicted the Americas in January 1991, and has caused more than one million cases and more than 10,000 deaths (3). It is also reflected in the prevailing high incidence of typhoid fever, hepatitis, amoebic and bacillary dysenteries, giardiasis, and other gastrointestinal infections. Drinking water is not the only pathway of these diseases but it is one of the most common. Its importance is also punctuated by the emergence of water-borne outbreaks of diseases not usually associated with drinking water, such as leptospirosis outbreaks in Central America in 1994-1995 and the control of an outbreak of flaccid paralysis in Cuba, probably due to the Coxsackie B virus, through the reintroduction of chlorine into the community water system after an extended period without chlorination because of the chlorine shortages and scarcity of fuel.

To provide the threatened populations with piped water systems that deliver microbiologically safe water would require enormous initial investments and the continuing input of financial and human resources. Capital investments for such systems commonly range between US $\$ 100$ and $\$ 150$ per person served. Although desirable, it is not realistic to expect such large investments to occur in the foreseeable future. Currently the great majority of developing countries are struggling just to maintain the current level of coverage during continuing demographic growth, mass migration, and the economic situation.

However, it is feasible for even the impoverished people of developing countries to enjoy the benefits of microbiologically safe water through community-based and community-funded initiatives that will have an annual cost ranging between US $\$ 1.50$ and US $\$ 4.00$ per family of five, including amortization of the initial investment. The intervention consists of enabling households to disinfect essential quantities of household water in specially designed containers for water storage and use, and enabling the production of the water disinfectant at the local level.

This is currently being demonstrated through intervention projects that are well advanced in Bolivia, Colombia, the Dominican Republic, Ecuador, Nicaragua, and Guatemala, and in the initial stages in Cuba, El Salvador, Honduras, Panama, and Peru. This intervention is possible and feasible because it requires only a small initial investment, a few minutes a day on the part of the household, and is sufficiently simple to carry out that it can be accomplished by any of the family members from children to the elderly. Furthermore it involves only minor changes in family lifestyle and community culture, doing things that for the most part are already being done, but doing them in a more effective and sanitary manner. In addition, the required infrastructure support is usually already in place, and where not, only slight adjustments are necessary to assure its adequacy. The intervention is community- 
based: the knowledge can be transferred horizontally from one community to another, and a revolving fund can be established to obtain a multiplier effect. In addition, it serves as a spearhead to initiate complementary community interventions of sanitation, health education and personal hygiene.

James Gustave Speth, Administrator of the United Nations Development Program (UNDP), said, "It is necessary to help people help themselves to a better lifewherever they are. The UNDP vision of sustainable human development is that it not only generates growth-it distributes the benefits equitably. It regenerates the environment rather than destroys it. It empowers people rather than marginalizes them. It gives priority to the poor, enlarging their choices and providing for their participation in decisions that affect their lives." This intervention is truly consonant with the wisdom of the statement.

\section{Current Situation}

The populations most threatened by waterborne diseases are the economically disadvantaged, whether they are located in urban or rural areas. Because this segment of the population typically receives water intermittently, regardless of the method of delivery (piped systems, water rank trucks, or hand hauling), the households must obtain adequate quantities of water when it is available, and then store it in containers for subsequent use when the delivery system is inoperative or unavailable.

Virtually every type of tank or container imaginable is being utilized for household water storage and most do not adequately protect the contents from contamination. Many are open without lid or cover. Used 55-gallon oil drums and open plastic and metal buckets are commonplace. Studies have shown that even if water is microbiologically safe upon its placement in such makeshift containers, it is quickly contaminated during storage and use, primarily by contact with human hands or contaminated utensils that are used to withdraw water, as well as the entrance of dust, animals, birds and insects when the vessel is inadequately covered (4-6). Under these circumstances, even when the water is initially disinfected, the subsequent contamination is often so great that it nullifies the disinfectant. The importance of a suitable household water container in the prevention of waterborne diseases is well documented $(7,8)$.

Households fail to disinfect water for a number of reasons. Many are not even aware of how important disinfecting drinking water is to human health, and, where awareness is present, the traditional method of disinfection through boiling is too costly to be carried out on a regular basis. Boiling sufficient water for drinking, processing and cooking of food, dish washing and hand washing (estimated to be about 40 liters per day for a family of five) will cost from $\$ 150$ to $\$ 150$ a year (7). Boiling only 10 liters of drinking water can even be too costly for most households in impoverished high-risk areas. Other serious disadvantages of boiling are that it does not provide residual protection if the water is re-contaminated during storage and handling, and, if it were used universally, would contribute heavily to deforestation $(9,10)$.

Chemical disinfectants can be considerably less expensive and some, such as various chlorine compounds, provide a residual disinfectant capacity that can help protect 
against recontamination. Unfortunately they are often not readily available in the threatened communities.

\section{Recommended Intervention}

The recommended intervention is for the households to obtain and utilize one or preferably two suitable water storage containers in which to disinfect and store the essential quantities of water that need to be free of pathogens, with the containers of a design that will protect the contents against re-contamination and enable the production and distribution of the water disinfectant to be managed at the local level.

Although a single container is adequate there is a great advantage in using two containers. With two, while one of them is being used, the other serves not only as a reserve but also a contact chamber in which exposure of the pathogens to the disinfectant can be extended for up to eight hours. During this long storage period the water temperature rises to room temperature. Both factors lead to more efficient inactivation of pathogens. Tests conducted under the PAHO project verified that viral and bacterial pathogens were eliminated and the cysts of E. histolytica and G. muris were killed or inactivated under these treatment conditions. The lengthy exposure of the microbes to the disinfectant and the higher temperature are advantageous in that they permit lower dosages of the disinfectant and reduce chlorine taste.

\section{Characteristics of a Suitable Container}

In recognition of the importance of the container in preserving water quality, $\mathrm{PAHO}$ and the U.S. Public Health Service's Centers for Disease Control and Prevention (CDC) studied container characteristics that would preclude contamination of the contents and facilitate disinfection at the household level. It was found that the following criteria are necessary and that they do not elevate the cost of the container beyond the financial capacity of poor households:

Appropriate shape and dimensions of the container with a volume between 10 and 30 liters so that it is not too heavy, fitted with handles to facilitate lifting and carrying, and a stable base to help prevent overturning.

Durable material, resistant to impact and oxidation, easy to clean, lightweight, and translucent. High density polyethylene is often the most appropriate material that is readily available.

An inlet which is large enough to facilitate filling but small enough to preclude the immersion of objects or hands into the water and fitted with a durable screw-on lid, preferably fastened to the container with a cord or chain. A diameter between 6 and $7.5 \mathrm{~cm}$ is optimal.

A device for measuring the correct amount of disinfectant to be dosed, incorporated into the container or into the flask which contains the disinfectant. A lid and/or a dropper can be designed to serve this purpose.

A durable faucet which is resistant to oxidation and impact, closes easily, and can discharge approximately one liter of water in about 15 seconds. 
A small air-inlet valve or capped opening that permits the entrance of air as water is being extracted.

Instructions for use of the container, disinfection of the contents, and cleaning the interior, permanently affixed to the container on a material that does not deteriorate when wet or moist.

A certificate that indicates the container complies with the requirements of the Ministry of Health or an equivalent appropriate authority.

\section{Characteristics of a Suitable Disinfectant}

The disinfectant should kill or inactivate pathogens that are likely to be encountered in the water sources being used under the conditions that exist during the disinfection process. The amount of elapsed time between the application of the disinfectant and the use of the disinfected water (contact time), the water quality parameters such as $\mathrm{pH}$, turbidity, and temperature as well as the degree of microbial contamination are factors which must be taken into consideration in the evaluation of a water disinfectant. The following are important characteristics to consider in selecting a disinfectant. It should:

Be reliable and effective in the inactivation of pathogens under a range of conditions likely to be encountered.

Provide an adequate residual concentration in the water to assure safe microbial quality throughout the storage period.

Not introduce nor produce substances in concentrations that may be deleterious to health, nor otherwise change the characteristics of the water so as to make it unsuitable for human consumption or aesthetically unacceptable to the consumer.

Be reasonably safe for household storage and use.

Have an accurate, simple, and rapid test for measurement of the disinfectant residual in the water which can be performed, when required, by local residents, or if necessary by a member of the household. (The DPD test fulfills this requirement and costs about $\$ 0.10$ per test. Tests for chlorine residuals do not need to be conducted routinely, but only when establishing the required dose of hypochlorine, spot checking, or special studies.)

Have an adequate shelf life without significant loss of potency.

Have a cost that is affordable for the household.

It is important to acknowledge that there is no perfect water disinfectant that will work optimally under all circumstances. Each has its advantages and disadvantages. Chlorine remains the most widely used water disinfectant in Latin America (I). Disinfection with chlorine has also been proven effective in the reduction of waterborne diseases in Latin America $(1,11)$. The demonstration projects identified an $0.5 \%$ sodium hypochlorite solution as having the best overall characteristics for both production at the local level and household water disinfection. 
Other disinfectants were considered. In one Bolivian community in which water sources are heavily polluted with organisms that are difficult to inactivate, a mixed oxidant solution was used instead of hypochlorite because it is a more potent disinfectant. The mixed oxidant solution is a disinfectant that is produced by the electrolysis of a salt solution using special catalytic electrodes to yield a number of oxidants including short-lived species of oxygen, ozone, chlorine dioxide, hydrogen peroxide and various chlorine species. This disinfectant was found to be very efficient in eliminating the pathogens and it was also found to improve taste and odors. Unfortunately this disinfectant had the disadvantage of a shorter shelf life, it was more costly than hypochlorite, and difficulties were encountered in operation and maintenance of the equipment.

Ozone was also considered since it is the most efficient of the chemical disinfectants, but it does not have a persistent residual, its concentration is difficult to determine, it is expensive, and it cannot be stored and therefore would have to be produced at each household. Iodine and iodine compounds can be effective water disinfectants, but the World Health Organization (WHO) does not recommend iodine for long-term disinfection of drinking water (12). Ultraviolet light is an effective disinfectant, but it is more expensive than hypochlorites, it does not provide a residual, it is not practical for the quality and quantity of water used, and equipment would have to be provided for each household. Various commercial disinfection tablets were considered and tested, but they were found to be much more expensive than sodium hypochlorite, most were not as effective as sodium hypochlorite, and none of them could be produced at the local level.

\section{Demonstration Projects}

PAHO has been collaborating with CDC, Germany's Gesellshaft Technische Zusammenarbeit (GTZ), and Italy's Centre Progetti Co-operazione (CPC), in carrying out demonstration projects aimed at testing the technical validity of this intervention, evaluating its socio-cultural acceptance, and demonstrating the feasibility of expanding such projects into national initiatives. All are small-scale projects ranging from several hundred up to a thousand participating households. Projects are in different stages of development in Bolivia, Columbia, Cuba, The Dominican Republic, Ecuador, El Salvador, Guatemala, Honduras, Nicaragua, Panama, and Peru.

The projects have the similar core of special water containers that comply with the previously described PAHO requirements along with the local production of disinfectants, but they otherwise vary considerably from one country to another, and even from one community to another. Table I summarizes the number of disinfection production units provided for each of the participating countries and the number of households provided with special water storage containers. It will be noted that the production capacity of the equipment for the production of water disinfectant greatly exceeds the requirements for the number of households provided with special water storage containers. This has been done because even the lowest capacity devices can supply large numbers of households, and it permits expansion of coverage to serve all of the households in the communities and possibly serve households in neighboring communities. 
TABLE I: Summary of Service Level Data at Projects for Disinfection at the Household Level

\begin{tabular}{|l|c|c|c|c|}
\hline Country & $\begin{array}{c}\text { Number of } \\
\text { units to } \\
\text { produce the } \\
\text { disinfectant }\end{array}$ & $\begin{array}{c}\text { Number of } \\
\text { households } \\
\text { with special } \\
\text { water } \\
\text { containers }\end{array}$ & $\begin{array}{c}\text { Potential } \\
\text { number of } \\
\text { households } \\
\text { that can be } \\
\text { supplied with } \\
\text { disinfectant }\end{array}$ & $\begin{array}{c}\text { Number of } \\
\text { containers } \\
\text { per } \\
\text { household }\end{array}$ \\
\hline Bolivia & 4 & 600 & 48,000 & 2 \\
\hline Colombia & 3 & 1,250 & 10,000 & 1 \\
\hline Cuba & 4 & NA & 80,000 & NA \\
\hline Dominican & 2 & 500 & 10,000 & 1 \\
Republic & 4 & 1,000 & 24,000 & 1 \\
\hline Ecuador & NA & NA & NA & NA \\
\hline El & 2 & 590 & 10,000 & 1 \\
\hline Salvador & NA & NA & NA & NA \\
\hline Guatemala & 3 & 750 & 12,500 & 1 \\
\hline Honduras & $15 p v$ & 1,100 & 37,500 & 1 \\
\hline Nicaragua & $1 p v$ & NA & NA & NA \\
\hline & $2 \mathrm{pv}$ & NA & NA & NA \\
\hline Panama & & & & \\
\hline Peru & 2 & & & 1 \\
\hline
\end{tabular}

$N A=$ information not available or incomplete.

$\mathrm{pv}=$ disinfectant production units powered by solar (photovoltaic cells) energy.

Various containers were evaluated by both PAHO and CDC. Several were found in the United States that complied with almost all of the requirements, and they were purchased and shipped to the initial demonstration projects in Latin America. As part of the project, after practical use, they were evaluated by both health officials and participants for suitability, durability, ease of use, preferable volume, and the design features listed earlier. Because the cost of shipping long distances as almost equal to the cost of the container, the need for local manufacture was apparent.

In Bolivia all of the containers have been 5 -gallon (20 liter) polyethylene containers that were manufactured in the United States, but the mold has been sold to a local manufacturer so they can be produced in Bolivia. Local production is scheduled to commence in 1996 and, depending upon public acceptance, may be mass produced to serve the entire country. In the Dominican Republic, Nicaragua, and Colombia the same 20 liter containers have been used, but in Columbia a 55 gallon ferrocement container which was produced locally was also tested. In Colombia, the GTZ is also financing a project in the private sector to design and produce a trial run of suitable plastic containers. In Guatemala and in Ecuador the containers were produced by retrofitting locally manufactured plastic containers with faucets. In Peru several designs have been produced and manufactured commercially, but all have a capacity of 20 liters. 
In Bolivia, Colombia and Nicaragua a small percentage of the participating households were also provided with a locally fabricated sand filter to pretreat the water before its disinfection in the household containers. Such pretreatment does increase the efficiency of disinfection and improve the aesthetic quality of the water.

Hypochlorite production devices from 5 different manufacturers are being used. Each has advantages and disadvantages, but any of them are capable of reliable production of a hypochlorite solution at the community level. All of them produce a solution of sodium hypochlorite through the electrolysis of a $3 \%$ salt solution. None of the installations are operating full time because the equipment production capacity exceeds the needs of the number of household provided with special containers, thereby allowing for considerable expansion of service as more households desire to participate.

Most of the installations use electricity from an electrical grid, but the neediest populations often do not have a grid. To serve small isolated communities without electricity in Nicaragua, 15 hypochlorite generators powered by photovoltaic panels were installed. Two photovoltaic-powered hypochlorite generators were recently installed in Peru and one in Panama. Because of the low voltage (6-12 volts) and continuous (DC) current requirements of the electrolysis cells for on-site production of sodium hypochlorite, photovoltaic panels are almost ideal for remote locations without electrical power grids. Use of an amp hour meter can assure consistent concentrations of sodium hypochlorite even with fluctuations in the sunlight.

Microbiological analysis of the water before and after disinfection in the special plastic water containers has been conducted, along with an evaluation of the methodology used in dosage of the disinfectants, the concentration of disinfectant necessary to achieve inactivation, and the contact time elapsed before use of the disinfected water (13). This was carried out under actual field conditions as well as carefully controlled laboratory conditions, and it was proven feasible to inactivate all of the waterborne pathogens, with the exception of Cryptosporidium oocysts, through application of 0.5 to $1.5 \mathrm{mg} /$ liter of hypochlorite (depending upon the microbial quality of the source water) to the water in the special container, and adequate retention time for the disinfectant to be in contact with the microbes $(13,14)$.

Of these projects, the Bolivian endeavor has received the most intensive follow-up to determine its epidemiological, social, and water-quality impacts in randomly selected control groups and intervention groups. It is actually comprised of a number of separate but carefully coordinated projects made possible through technical and financial collaboration of PAHO, CDC, U.S. Agency for International Development (USAID), the University of North Carolina, Germany's Gesellshaft Technische Zusammenarbeit, Rotary International, the Bolivian Ministry of Health, and with support from various local agencies and institutions as well as the private sector.

The epidemiological studies in Montero, Bolivia are being carried out in greater depth and are farther advanced than in the other countries. Patients in both the control and the intervention groups were tested for Salmonella, Shigella, Campylobacter, Vibrio cholerae enterotoxigenic and enteropathogenic E. Coli., E. Histolitica, Giardialamblia, and rotavirus (14). The epidemiological studies in Nicaragua, Colombia and Cuba are small in scope and at an earlier stage than in Bolivia. A project not being sponsored by PAHO but which is patterned after the Bolivia project is being carried out in the 
"colonias" along the border areas of Juarez, Mexico and El Paso, Texas in the United States, and is beginning to produce favorable epidemiological results (15).

The preliminary report of the project in Montero, Bolivia disclosed 85 episodes of diarrhea in the intervention group of 417 persons and 161 episodes of diarrhea in the control group of 403 persons after 5 months of applying the intervention (14). The number of episodes per family was decreased by $44 \%$ by this intervention. The age groups that benefited the most from the safe water were those under one year of age and those between the ages of 5 and 14 years (14). The age group between 1 and 4 was least affected, probably because of their newly acquired mobility and tendency to place things in their mouth. The households in extreme poverty also benefited more from this intervention than those in a higher income bracket. This study also disclosed that Campylobacter was isolated in $21 \%$ of the cases of diarrhea, rotavirus in $12 \%$, Giardia lamblia in $23 \%$, Ascaris lumbricoides in $42 \%$, and other parasites in $30 \%$ of the cases. E. Histolitica was encountered in only $1 \%$ of the cases of diarrhea. Thirty percent of the patients were found positive for more than one parasite. The number of patients that tested positive for Campylobacter is unusually high.

Initial data from the Nicaragua project show a decrease of approximately $50 \%$ in the incidence of diarrhea in the intervention group compared to the control group. A report from Colombia of a longitudinal study indicates about a $60 \%$ reduction in the incidence of cholera after this intervention was implemented; however it is uncertain that this decrease was due solely to the improvement in water quality since other interventions were implemented at the same time. The first phase of a project carried out by the University of Texas at EI Paso on the US/Mexico border yielded very encouraging results. At the start of the project, on the Mexican side only $24 \%$ and on the US side only $29 \%$ of the household water supplies had a free residual chlorine level of $0.5 \mathrm{mg} /$ liter or higher; by the end of the first phase of the project this figure rose to $82 \%$ on the Mexican side and to $77 \%$ on the US side. After the provision of safe water containers and disinfection along with extensive community education, the prevalence of household cases of diarrhea on the Mexican side of the border fell from $29 \%$ to $7 \%$, and on the United States side from $22 \%$ to $6 \%$, by the end of the first phase of the project (15).

\section{Community Education, Participation and Mobilization}

The potential of this simple and low-cost water treatment and storage method to provide safe water and thus reduce exposure to waterborne pathogens has been demonstrated. However, this is only one step towards the successful implementation of this system in high risk areas of the world. The volition of the people themselves, which stems from their a priori recognition that contaminated water and unsafe storage lead to poor health, is essential for the sustainability of such a program. Proper education in hygiene, and frequent household visits by local health personnel to demonstrate and reinforce correct use, storage, and maintenance of the disinfectant and containers, are essential. Community mobilization should also consider the method and frequency of payment by the household for the disinfectant, the type and volume of the flask for the hypochlorite, the method of distributing the disinfectant, and the operation and maintenance of the equipment used to produce the disinfectant. Cooperation with the private marketing sector can in some situations be an effective strategy to help assure sustained availability of containers and disinfectant for every family. The communication media, such as 
radio, television and newspaper, have an important role to play in the promotion and education regarding the importance and means of disinfecting of household water and assuring its safe and sanitary storage and use. Education of the households about the importance of proper disinfection, handling and use of the water can benefit from strong support by national and local public health authorities and community leaders. Incorporating this education into the public school programs has also been shown to be advantageous in promulgating these practices. Widespread use of this technology in public settings such as schools, markets and community centers not only increases protection but also enhances the formation of good hygienic habits.

It is usually preferable to have a community-based operation that is supported by national, state, or even municipal agencies and organizations than to have a national program which expects its operations to be supported by the community. This is a fine but important distinction involving ownership, commitment, cooperation and determination of the most effective level to carry out and finance day to day operations, long term planning, mass purchasing etc. The privatization of local production and distribution of hypochlorite in some situations may be the preferred option to obtain sustainability.

It is also important for the community to be involved to the greatest extent possible in evaluation of the effectiveness of the measures taken to assure the microbiological quality of the water and the benefits derived thereby. Feedback of quantitative and qualitative health data from the hospitals, clinics and public health entities to the community, in a form which is understandable to the community, is desirable to enable an accurate assessment by the community and the individual households.

As clearly demonstrated by these projects, this technology makes it possible for households to have microbiologically safe water at a cost that even the very poor can afford, and for health benefits commensurate with water quality improvement to be derived. However, for this to occur it is essential that the individual households unfailingly carry out the task on a daily basis, and that the community itself assure the availability of water disinfectant and suitable water storage containers for purchase by each household. This requires education and motivation of the households and mobilization of the community.

Each country project included a component to develop a specific plan for community mobilization. Knowledge, attitudes and practices were evaluated in the participating communities with special attention given to the health benefits to be derived by disinfection of drinking water and to willingness to pay. Training and community education regarding the need for safe microbial water quality and the methodology to carry it out was an integral part of each project, in addition to other public information programs.

Each project utilized community participation in the development of a plan for the management of the production and distribution of the disinfectant at the local level, and to implement the plan. As was expected, a number of different methods were set forth. Some communities utilize the health center or hospital to manage the production and distribution of the disinfectant. Some have set it up as a cooperative community venture and others as a private-sector operation. Another community utilizes the refuse collectors who visit each household once a week to vend the sodium hypochlorite door to door. An attempt was made to compare and evaluate 
the different methods of providing and distributing the water disinfectant at the local level, and the sustainability of these mechanisms, but none was found to be vastly superior to the others. All of them seem to work, and only time will be the real test of their sustainability. The most important requirement for success is for them to fit the culture of the community, and for them to be strongly endorsed by local leaders and health authorities.

\section{Costs}

Disinfection of only the essential household water is inherently less expensive than disinfecting the water in a piped distribution system, because a smaller quantity of water is disinfected. The daily water consumption for people connected to a piped water system ranges between 80 to 200 liters per person, whereas for people not connected to a piped water system, the daily consumption of water is primarily for essential purposes and this generally ranges between 5 and 10 liters per person. In these projects a typical family of five used about 40 liters of water daily for essential purposes.

Cost estimates were made for the various components of this intervention in all of the countries, and a cost-benefit study was carried out in Bolivia. A prevention effectiveness model for a Bolivian community of 10,000 in which the intervention was assumed to reduce diarrheal incidence by $10 \%$ showed prevention of 600 cases of diarrhea, 100 hospitalizations, and 5 deaths during a three year period (8).

The retail cost of a container which complies with the PAHO criteria generally ranges between US $\$ 4.00$ and $\$ 6.00$. Depending upon the location of the manufacturer, the shipping and handling costs can range from as little as US $\$ 0.50$ for nearby incountry shipment to as high as $\$ 5.00$ for distant overseas shipment. The life of the containers is estimated to be at least 5 years and probably more than 10 years. Some of the more durable ones that have received reasonable care have actually lasted 19 years and are still in use. PAHO used a container life of 7 years in making the cost estimates.

Typical prices of sodium hypochlorite generators range between $\$ 1,500$ and $\$ 2,000$ for units which produce one kilogram of available chlorine in a 24 hour period. In general, the unit cost per kilogram of production capacity declines with larger capacity devices. One unit which produces 3 kilograms in 24 hours had a retail price of $\$ 1,600$ in 1995 .

In some situations it is more efficient and less costly to produce the sodium hypochlorite at a central location and distribute it to distant communities in bulk, to be bottled locally, and in others it is more appropriate and certain to produce and bottle it at the local level.

The sodium hypochlorite for the water disinfectant is the component of the intervention with the least cost. The cost of producing the sodium hypochlorite solution at the community level varies widely from one location to another primarily because of large differences in the cost of salt, electricity, and labor, and to a lesser extent because of differing amortization rates and equipment efficiency. The estimated cost per kilogram of available chlorine produced ranges from about $\$ 2.50$ to $\$ 5.00$, with an average of slightly less than $\$ 3.00$ (16). A year's supply of $0.5 \%$ sodium hypochlorite (at a production cost of $\$ 3.00 /$ kilogram of available chlorine) for 
a typical family dosing at a rate of $2 \mathrm{mg} /$ liter and using 40 liters of water per day for drinking, cooking, dishwashing and other essential purposes, is less than $\$ 0.10$. The cost of bottling and distributing the hypochlorite in the community raises this to about $\$ 1.00$ /year if the flask containing the sodium hypochlorite solution is reused.

With data from the demonstration projects, PAHO estimates that the total annual cost for the water containers and the production, bottling, and distribution of the water disinfectant range roughly between US $\$ 1.00$ and US $\$ 4.00$ per household. The variation in cost is primarily due to the number of containers per household, the cost of the water container, and the method used to distribute the water disinfectant to the household. It is important to acknowledge that more than $95 \%$ of the total cost is reflected in the special water container, the hypochlorite flask, and in the distribution of the disinfectant to the households, and less than $5 \%$ in the sodium hypochlorite solution.

\section{Conclusions}

1.Microbiologically unsafe drinking water is a serious public health problem affecting a very large segment of the population of Latin America and the Caribbean. It is one of the predominant causes of morbidity and mortality.

2. The combined effect of population growth, alarming poverty levels, emerging diseases, and diminishing resources for organized patterns of social participation are forcing the search for innovative methods of providing low-cost safe drinking water. As Robert McNamara has stated, structural adjustment is potentially socially destabilizing in the long run.

3. It is feasible for the economically disadvantaged families of Latin America and the Caribbean to have microbiologically safe drinking water through household application of sodium hypochlorite and the use of special water containers that prevent re-contamination of the contents. The cost of this is so little that even the poorest households can afford to pay for the entire cost of this improvement. The added value of this simple methodology is the improvement of the conditions of living for women and girls traditionally given the role of water carriers.

4. Household-level disinfection of water can significantly reduce the incidence of waterborne disease in communities that lack a microbiologically safe water supply. Even though drinking water is not the sole route of transmission of many gastrointestinal diseases, it is a very important one, particularly for the economically disadvantaged, and curtailing this pathway through disinfection at the household level results in a significant reduction in disease incidence. The use of this technology in public sites such as markets, schools, and health centers has a strong positive effect on health and on the horizontal transfer of information for self-implemented health protection practices.

5. Between 40 and 60 liters per day is the quantity of microbiologically safe water necessary for a typical Latin American household for drinking, cooking, food preparation and other essential household purposes which require water that is free of pathogens.

6. The water disinfectant that is overall the most suitable is a hypochlorite solution with a concentration between $0.5 \%$ and $1.0 \%$. Higher concentrations tend to lose 
their strength too rapidly to provide a useful shelf life. Depending upon the conditions, a $0.5 \%$ concentration of sodium hypochlorite has a useful shelf life of 50 to 60 days.

7. It is feasible and affordable for sodium hypochlorite solutions to be produced at the local level through the electrolysis of a solution of common salt. There are five manufacturers of devices to produce the small quantities of sodium hypochlorite that are needed, and it has been demonstrated that they function well under the actual community conditions. The operation and maintenance of this equipment is well within the capability of almost any community.

8. Where there is no electrical grid, solar energy (photovoltaic panels) can be used to provide the energy necessary for the electrolysis.

9. The total cost of producing and bottling sodium hypochlorite in the community, including amortization and operation of equipment, materials, maintenance, energy, and labor, ranges from about $\$ 0.25$ to $\$ 0.60$ per family served per year.

10. Projects of this type can be sustained as a micro-enterprise, a community cooperative, or as part of the local health system.

11. The national production of suitable household water containers and local production of water disinfectants through micro-enterprises can result in increased job opportunities and income generation.

\section{Recommendations}

1. National and local governing bodies of developing countries should carry out projects and studies to test the validity and feasibility of disinfecting water at the household level in special containers, along with production of water disinfectants at the local level, particularly for isolated communities, rural areas, unserved marginal urban areas and indigenous settlements where conventional water projects are difficult to finance and implement.

2. The private and public sector of developing countries should collaborate in the national or local production of suitable household water containers to assure their availability at an affordable price at the community level where they are needed.

3. International lending agencies such as the World Bank and the Inter-American Development Bank and bilateral agencies should accept and support this method of providing safe water as an interim means of assuring safe water until such time that comprehensive but costly safe water projects are functioning.

4. National economic and planning agencies that are striving to improve the conditions of the economically disadvantaged should be made aware of the affordability, cost effectiveness and efficiency of this public health measure and its impact on poverty alleviation.

5. Politicians should support initiatives to assist communities and/or enterprises to obtain loans to purchase equipment and supplies necessary to carry out this intervention. 
6. Local governments and NGOs should look at this intervention as one of the best short-term measures to provide safe water that also has significant impact on community empowerment and self-reliance.

\section{References}

1. Reiff, R M. "Balancing the Microbial and Chemical Risks in Drinking Water in Gunter Craun, ed. The Status of Drinking Water Disinfection in Latin America and the Caribbean: Water Quality in Latin America. Washington, D.C.: ILSI Press, 1996, pp. 91-105.

2. World Bank. World Development Report 1993: Investing in Health. Washington D.C., 1993.

3. Swerdlow, D. L., Mintz, E. D., Rodriquez, M., et al. "Waterborne Transmission of Epidemic Cholera in Trujillo, Peru: Lessons for a Continent at Risk," Lancet 340 (1992): 28-32.

4. Deb, D. C., et al. "Studies on Interventions to Prevent El Tor Cholera Transmission in Urban Slums," Bulletin of the World Health Organization 64 (1986): 127-31.

5. Han, A. M., Oo, K. N., Midorikawa, Y., and Shwe, S. "Contamination of Drinking Water During Collection and Storage," Trop. Geogr. Med. 41 (1989): 138-40.

6. Tuttle, J., Ries, A. A., Chimba, R. M., Perera, C. U., Bean, N. H., and Griffin, P. M. "Antimicrobial Resistant Epidemic Shigella Dysenteriae Type I in Zambia: Modes of Transmission," J. Infect. Dis. 171 (1995): 371-75.

7. Witt, V. M., and Reiff, F M. La Desinfeccion del Agua A Nivel Casero En Zonas Urbanas Marginales Y Rurales. PAHO/HPE, Serie ambiental no. 13. Washington, D.C., 1993.

8. Mintz, E. D., Reiff, F. M., and Tauxe R. V. "Safe Water Treatment and Storage in the Home," JAMA 273 (1995): 948-53.

9. Gilman, R. H., and Skillicorn, P. "Boiling of Drinking Water: Can a Fuel-scarce Community Afford It?," Bull. World Health Organ. 63 (1985):157-63.

10. DeKoning, H. W., Smith, K. R., and Last, J. M. "Biomass Fuel Consumption and Health," Bull. World Health Organ. 63 (1985):11-26.

11. Bersh, D., and Osorio, M. "Estudios de la Diarrhea en Quindio Colombia: Problemas Relacionados con el Tratamiento de Aguas," Soc. Sci. Med. 21 (1985): 31-39.

12. World Health Organization. Guidelines for Drinking Water Quality. Vol. 1, 2nd edition, Geneva, 1993.

13. Quick, R. E., Venczel, L. V., Gonzalez, O., Mintz, E. D., Highsmith, A. K., Espada, A., Damiani, E.,.Bean, N. H., de Hannover, E.H., and Tauxe, R. V. "Narrow-mouthed Water Storage Vessels and In Situ Chlorination in a Bolivian Community: A Simple Method to Improve Drinking Water Quality," Am. J. Tropical Medicine and Hygiene 54 (1996): 511-16.

14. Quick, R. E., and Venczel, L.V. El Programa de Desinfeccion Casera y Almacenamiento Seguro de Agua de Montero, Bolivia: Informe Preliminar. April 1995.

15. Vera, B., and Besseneckei. C. Agua Para Beber. Provision of Safe Drinking Water. A Report of Phase I. University of Texas at El Paso, Center for Environmental Resource Management, March 1995. 
16. Proceedings of the Primer Simposio International sobre Tecnologias para la Produccion de Desinfectantes a Nivel Local, Santiago de Cuba, June 4-6, 1995. To be published by PAHO in 1996.

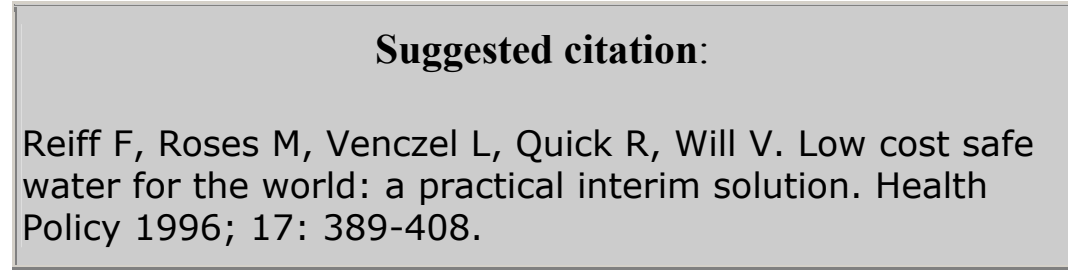

